\title{
DEMONSTRATION OF ORIENTAL SORE AND ITS PARASITE.
}

By Sir PATRICK MANSON, K.C.M.G., M.D., F.R.S.

(Friday, November 15th, 1907.)

Sir Patrick Manson said that, fortunately, he had an opportunity of demonstrating a typical example of the sore, which was variously known by several names, such as Delhi boil, Bouton d'Aleppo, etc. That this was a case of the disease had been proved by the microscope, which showed the characteristic parasite in enormous profusion. The Society was deeply indebted to the patient, himself a medical man, for his complacency and courtesy in having come there at much inconvenience to himself, and not without considerable suffering. He was a medical man, of about forty-one years of age, and had been working in Palestine for a considerable period. In June last he had to go to Baghdad, where he remained for nine months. On his return, and while at sea, some three weeks after be left that city, he saw what he thought was a mosquito bite on the back of his left hand: it was deep red, irritable, and itchy. Similar papules appeared at the same time on the dorsum of his left foot, and on the front of his right shin ; they were dry and scaly, and gradually the scurf and scales accumulated, and, mixing with exuding lymph, hardened into crusts. After several weeks the crusts fell off, leaving a superficial ulcerated surface, which had an indurated base and elevated edges. This sore extended until it was $2 \mathrm{in}$. in diameter, when fungating granulations sprang up almost completely covering the eroded surfaces and preventing healing; but recently these granulations had be- 
come dropsical and atrophied, and attempts at true cicatrisation had now begun to appear. That was to say, the disease had reached its final stage after lasting nine or ten months.

There were many interesting points in the history, the features, and the affinities of Oriental sore. First, it was protective against itself when it had run its course, the patient obtaining in most instances permanent immunity against the disease. Another characteristic was the uncertainty of the incubation period, which was sometimes short, so much so as to be almost an immediate sequence of infection and sore, in other instances running into many months. A lady missionary from Delhi whom he had recently seen developed Oriental sore in the South of France, five months after she had left the place of infection, and that circumstance, viewed in connection with immunity, was an interesting and important feature. Still another point of interest was that the disease occurred almost invariably on exposed parts of the body-on parts that were not generally covered by clothes-and that would lead to the inference that infection took place by some animal which could readily attack exposed parts. Insects, such as bugs and fleas, were thus ruled out, but mosquitoes and flies, for instunce, might be effective carriers, as they were likely to convey it only to exposed places.

The disease, too, was inoculable. He himsulf had not been successful in inoculation experiments; but there was no doubt about inoculability. Apart from his own experience, that had been abundantly confirmed. Dr. Daniels, who was not likely to fail when care and dexterity in manipulation were required, had, however, made many inoculations with him without success, and he thought he had a good explanation for their failure. They had not succeeded in the experiments which they made upon dogs, rabbits, monkeys, and sheep, because the parasite of the 
disease had passed the active stage, and was in an involuted or morbid condition. That, no doubt, too, was the explanation of the results which had recently been published by James. Deputed by the Indian Government to investigate the connection between the parasite discovered by Wright and the disease, Major James found, in Delhi, that only in a certain proportion of cases could he find in the scrapings of sores the characteristic organism. In many cases of undoubted Oriental sore, it was absent. As regarded the patient that evening, that too was the condition; whereas at first there were swarms of parasites crowding the cells and tissues, now they were extremely rare and difficult to find, and there could be little doubt but that these organisms were in the involution stage. But this mysterious malady had a still more interesting and noteworthy feature than all these. That was the relationship of Oriental sore to the deadly disease kala-azar. Per se, Oriental sore did not endanger life; though protracted, the tendency was to cure, and we could inoculate it without apprehension of serious evil. Kala-azar, on the contrary, never healed; it was most invariably fatal; and it would be, therefore, entirely unjustifiable to inoculate kala-azar into any human being. Yet the parasite of Oriental sore and the parasite of kala-azar were, so far as could be seen with the microscope, identical. He said morphologically, but perhaps not biologically, identical. And this fact gave rise to many questions and speculations. Were they of the same species? In their relations there was a unique opportunity of investigation, and perhaps of discovery. Of the connection between the Leishman-Donovan body and Oriental sore on the one hand, and kala-azar on the other, there could be little doubt; but it was only by successful inoculation experiments that the information about kala-azar, of which they stood so much in need, could be obtained. Assuming that the parasites were absolutely 
identical, as Oriental sore immunised against itself it ought also to immunise against kala-azar. An opportunity to test that had recently presented itself at the School of Tropical Medicine. They had, in hospital, a case of Oriental sore, and at the same time a case of kala-azar, and he had been able to obtain the consent of the patient who was suffering from kala-azar to be inoculated with Oriental sore. Two students of the school volunteering to act as controls of the virulence of the inoculated matter were inoculated at the same time, but the result was failure; none of the inoculations took. Still, he would much like to get another opportunity to repeat that interesting experiment with an Oriental sore in an earlier stage. It was essential that one should have a thoroughly reliable virus, and at the same time a suitable case of kala-azar. The former he was endeavouring to start and keep going, by means of monkeys, etc.; the latter would, no doubt, in time present itself. If any who were present that evening could assist him with an opportunity, or avail themselves of an opportunity to test this hypothesis, the result, he believed, might encourage them to continue in a new line the attempts now being made to find a cure for kala-azar.

Again, was Oriental sore constitutional ; was it a systemic disease; or was it one that, if the local lesion were cut out or destroyed, would thereby be cured? He considered that Oriental sore was a general infection, and that was probable, because, for one thing, a patient, on obtaining immunity, obtained general immunity. If the active sore was eradicated in one place, it would appear in another, and it could only be effeetively cured when the parasite had run its course and reached the involution stage. 